\title{
A comparison of $0.075 \%$ and $0.15 \%$ of ropivacaine with fentanyl for postoperative patient controlled epidural analgesia after laparoscopic gynecologic surgery
}

\author{
Hyun Chul Jung, Hyo Jung Seo, Deok Hee Lee, Sang-Jin Park \\ Department of Anesthesiology and Pain Medicine, Yeungnam University College of Medicine, Daegu, Korea
}

\begin{abstract}
Background: A motor blockade of lower limbs interferes with early ambulation and limits the usefulness of patient-controlled epidural analgesia (PCEA). The concentration of local anesthetic solution is a major determinant for motor block with PCEA. We compared the effects of epidural infusion of $0.075 \%$ ropivacaine with $0.15 \%$ epidural ropivacaine on postoperative analgesia, motor block of lower limbs, and other side effects. Methods: A total of 70 patients undergoing laparoscopic gynecologic surgery received epidural infusions (group R1, 0.15\% ropivacaine with fentanyl; group R2, 0.075\% ropivacaine with fentanyl). Pain score, motor block, and side effects (hypotension, nausea, vomiting, pruritus, urinary retention, dizziness, and numbness) were measured.

Results: There were no significant differences in the demographic profiles between the groups. Pain scores of the group R1 and the group R2 were not significantly different. Motor block was more frequent in the group R1 $(0.15 \%$ ropivacaine with fentanyl) than in the group $\mathrm{R} 2(0.075 \%$ ropivacaine with fentanyl).

Conclusion: Lower concentration of ropivacaine $(0.075 \%)$, when compared with higher concentration of ropivacaine $(0.15 \%)$, seemed to provide similar analgesia with less motor blockade of the lower limbs for the purpose of PCEA.
\end{abstract}

Keywords: Epidural analgesia; Ropivacaine; Side effect; Concentration

\section{INTRODUCTION}

Patient-controlled epidural analgesia (PCEA) with opioids, although more effective than intravenous patient controlled analgesia (IV-PCA) for postoperative pain control, is associated with frequent unwanted side effects including nausea, vomiting, pruritus, hypotension, motor blockade, and urinary

Received: April 11, 2017, Revised: May 16, 2017

Accepted: May 17, 2017

Corresponding Author: Sang-Jin Park, Department of Anesthesiology and Pain Medicine, Yeungnam University

College of Medicine, 170 Hyeonchung-ro, Nam-Gu,

Daegu 42415, Korea

Tel: +82-53-620-3366, Fax: +82-53-626-5275

E-mail: apsj0718@naver.com retention [1]. In particular, an intense motor blockade of the lower limbs by epidural infusions of local anesthetics has been known to interfere with early ambulation and limit the usefulness of PCEA. Ropivacaine is a new local anesthetic that has been gaining popularity in epidural analgesia due to less motor blockade and less toxicity. The $0.2 \%$ formulation of ropivacaine produces effective postoperative analgesia and less motor blockade compared with bupivacaine [2]. However, a previous study has reported that a lumbar epidural infusion of $0.2 \%$ ropivacaine caused frequent motor blockade of the lower limbs (30-63\%) [1].

A concentration of local anesthetic solution is a major determinant of motor blockade with PCEA [2]. An epidural infusion of 0.1 or $0.15 \%$ ropivacaine with opioid provided satisfactory postoperative pain management $[3,4]$. Therefore, a

Copyright (C) 2017 Yeungnam University College of Medicine

This is an Open Access article distributed under the terms of the Creative Commons Attribution Non-Commercial License (http://creativecommons.org/licenses/by-nc/4.0/) which permits unrestricted non-commercial use, distribution, and reproduction in any medium, provided the original work is properly cited. 
lower concentration, lesser than $0.1 \%$ of ropivacaine may provide comparable postoperative analgesia with lesser motor blockades. This study was designed to evaluate the effects of low concentration of ropivacaine $(0.075 \%)$ with fentanyl on postoperative analgesia, motor block of lower limbs, and other side effects from PCEA, when compared with 0.15\% ropivacaine with fentanyl.

\section{MATERIALS AND METHODS}

This study was approved by the local institutional review board, and informed consent was obtained from all participants. Patients aged between 18 and 65 years with the American Society of Anesthesiologists (ASA) physical status I or II and undergoing laparoscopic gynecologic surgeries were considered for inclusion. Exclusion criteria were as follows: ASA physical status of greater than III, patients with a history of hypertension or diabetes mellitus, peripheral neuropathy, drug or alcohol abuse, body mass index of more than $30 \mathrm{~kg} / \mathrm{m}^{2}$, and inability to understand the use of PCEA or visual analogue scale (VAS).

This study was conducted in a randomized, double-blinded method. Patients were randomized using a computer randomization program into one of two groups: group R1 was $0.15 \%$ ropivacaine and fentanyl, while group R2 was administrated with $0.075 \%$ ropivacaine and fentanyl. Two anesthesiologists carried out the study. One was responsible for preparing the epidural drug. The other conducted anesthesia and assessed the pain scores and side effects.

In the operating room, routine monitoring devices were applied including electrocardiography, non-invasive blood pressure, pulse oximetry, and bispectral index (BIS). After confirmation of the baseline vital signs, Hartman's solution $500 \mathrm{~mL}$ infusion was started. Epidural catheter was placed $3 \mathrm{~cm}$ into the epidural space at the L2-3 or L3-4 interspaces. The catheter was fixed with sterilized fixing tape to prevent catheter dislodgement or removal, and then $3 \mathrm{~mL}$ of $2 \%$ lidocaine and 1:200,000 epinephrine were injected as a test dose. After confirmation of negative response to the test dose, patients received ropivacaine $0.15 \%$ with $2 \mu \mathrm{g} / \mathrm{mL}$ of fentanyl (group R1) or ropivacaine $0.075 \%$ with $2 \mu \mathrm{g} / \mathrm{mL}$ of fentanyl (group R2) $10 \mathrm{~mL}$. If the sensory level of the block did not reach T8 dermatome, patients received an additional 5-10 $\mathrm{mL}$ dose of ropivacaine (ropivacaine $0.15 \%$ with $2 \mu \mathrm{g} / \mathrm{mL}$ of fentanyl or ropivacaine $0.075 \%$ with $2 \mu \mathrm{g} / \mathrm{mL}$ of fentanyl). An infusion device (Accumate 1000, WooYoung Medical, Seoul, Korea) containing the study drug was connected to each patient. Study drug was prepared as follows: In group R1, $0.15 \%$ ropivacaine was mixed with $2 \mu \mathrm{g} / \mathrm{mL}$ of fentanyl with an infusion rate-bolus dose-lockout interval of $10 \mathrm{~mL} / \mathrm{hr}-5 \mathrm{~mL} / 15 \mathrm{~min}$; group R2, $0.075 \%$ ropivacaine was mixed with $2 \mu \mathrm{g} / \mathrm{mL}$ of fentanyl, 10 $\mathrm{mL} / \mathrm{hr}-5 \mathrm{~mL} / 15 \mathrm{~min}$, respectively. After confirmation of adequate sensory block to T8 dermatome (tested by pinprick) and Hartman's solution $500 \mathrm{~mL}$ infusion was finished, general anesthesia was conducted with propofol $1.5 \mathrm{mg} / \mathrm{kg}$ and rocuronium $0.8 \mathrm{mg} / \mathrm{kg}$. A $3 \mathrm{vol} \%$ of sevoflurane was used with oxygen and air $\left(\mathrm{FiO}_{2}\right.$ 0.5) during the induction period. After achieving a deep neuromuscular blockade, which was confirmed by train of four monitoring, endotracheal intubation was performed, and sevoflurane was controlled in the range of BIS 40 to 60 .

Epidural analgesia was assessed 5 times: just before leaving the post-anesthesia care unit (PACU), $6 \mathrm{hr}, 12 \mathrm{hr}, 24 \mathrm{hr}$, and $36 \mathrm{hr}$ after the surgery. Pain was assessed using the VAS score where 0 indicated no pain and 10 indicated worst pain possible during rest (Vrest), cough or movement $(\mathrm{Vc} / \mathrm{m})$. Motor blockade of the lower limbs was assessed by a modified Bromage scale (0: no motor block, 1 : inability to raise extended leg, 2: inability to flex knee, 3: inability to flex ankle) [5]. The level of sensory blockade was also checked using the pinprick method at $6 \mathrm{hr}$ after surgery. Patients were instructed to press the PCA button for a bolus injection if their self-reported pain score exceeded 3 at rest. If pain did not subside after the bolus injection, it was also recorded and managed by IV bolus of fentanyl $50 \mu \mathrm{g}$. Complications, such as nausea and vomiting, dizziness, hypotension, urinary retention, numbness of legs, and pruritus, were also assessed. Hypotension was classified as systolic blood pressure $<90 \mathrm{mmHg}$. Urinary retention was checked by an urologist at $6 \mathrm{hr}, 12 \mathrm{hr}, 24 \mathrm{hr}$, and $36 \mathrm{hr}$ after surgery. It was classified as a bladder volume of greater than $400 \mathrm{~mL}$ with the inability to void spontaneously and single catheterization was performed. Bladder ultrasonography was performed to measure the bladder volume.

The primary outcome measure was VAS at $6 \mathrm{hr}$ after surgery. This prospective investigation was performed as a preliminary study. A minimum sample size of 31 patients per group was required to detect a difference of VAS among the groups with a power of 0.8 and a type one error of 0.05 . In consideration of a dropout rate of about 20\%, 74 patients 
were enrolled in this study. Data was computed and analyzed by using IBM SPSS version 23.0 (IBM Co., Armonk, NY, USA). The data are presented as the numerical values or the mean (SD) as appropriate. Normally distributed continuous data were analyzed using the independent sample t-test. Continuous variables that were non-normally distributed were analyzed via the Mann-Whitney U-test. Categorical data such as complication, motor block, and sensory level were analyzed using chi-square test or Fisher's exact test as applicable. $p<0.05$ was considered statistically significant.

\section{RESULTS}

Of the 74 patients enrolled, 70 completed the trial. There were 33 patients in the group R1 and 37 patients in the group R2. Four patients were excluded from the study due to the following reasons: refusal to provide consent ( 2 in the group R1) and failure of nerve block (2 in the group R1). Demographic and clinical characteristics were not different between the two groups (Table 1).

There were no significant differences between the group $\mathrm{R} 1$ and R2 in the VAS score at rest and movement (Table 2). The number of patients receiving supplementary postoperative analgesia with fentanyl was not significantly different between the two groups (Table 2). The incidence of motor blockade in the group R1 was higher than that in the group R2 at PACU, $6 \mathrm{hr}$, and $12 \mathrm{hr}$ after surgery (Table 3). The total number of patients showing complications did not differ between the two groups (Table 4). The most frequent side effect was nausea and vomiting, with a similar incidence in both groups (24\% and 27\%). However, urinary retention was more common in the group R1 $(p<0.05)$. Sensory blockade was most common at $\mathrm{T} 8$ dermatome in patients with epidural analgesia, and there were no significant differences between

Table 1. Patients' demographic and clinical characteristics

\begin{tabular}{lcc}
\hline & Group R1 $(\mathrm{n}=33)$ & Group R2 $(\mathrm{n}=37)$ \\
\hline Age $(\mathrm{yr})$ & $42.64 \pm 9.53$ & $42.95 \pm 8.50$ \\
Height $(\mathrm{cm})$ & $159.82 \pm 6.09$ & $158.24 \pm 5.56$ \\
Weight $(\mathrm{kg})$ & $59.12 \pm 10.08$ & $57.95 \pm 7.97$ \\
Op duration (min) & $53.91 \pm 25.4$ & $67.89 \pm 36.57$ \\
\hline
\end{tabular}

Values are presented as mean \pm standard deviation.

Group R1, 0.15\% ropivacaine+fentanyl; group R2, 0.075\% ropivacaine +fentanyl.

Op, operation.

There are no significant differences between the groups. group R1 and group R2 (Table 5).

Table 2. Visual analogue scale pain score

\begin{tabular}{ccc}
\hline & Group R1 $(\mathrm{n}=33)$ & Group R2 $(\mathrm{n}=37)$ \\
\hline At rest & & \\
PACU & $2.42 \pm 0.94$ & $2.32 \pm 0.67$ \\
$6 \mathrm{hr}$ & $2.55 \pm 1.03$ & $2.38 \pm 1.04$ \\
$12 \mathrm{hr}$ & $1.82 \pm 1.13$ & $1.84 \pm 1.26$ \\
$24 \mathrm{hr}$ & $1.15 \pm 1.12$ & $1.32 \pm 1.13$ \\
$36 \mathrm{hr}$ & $0.88 \pm 0.78$ & $0.73 \pm 0.77$ \\
At cough and move & & \\
PACU & $3.79 \pm 1.02$ & $3.73 \pm 1.15$ \\
$6 \mathrm{hr}$ & $3.91 \pm 1.53$ & $3.60 \pm 1.48$ \\
$12 \mathrm{hr}$ & $2.67 \pm 1.36$ & $2.95 \pm 1.35$ \\
$24 \mathrm{hr}$ & $2.61 \pm 1.66$ & $2.46 \pm 1.30$ \\
$36 \mathrm{hr}$ & $2.52 \pm 1.62$ & $2.35 \pm 1.55$ \\
No of rescue analgesia & 13 & 8 \\
\hline
\end{tabular}

Values are presented as mean \pm standard deviation or numbers. Group R1, 0.15\% ropivacaine+fentanyl; group R2, 0.075\% ropivacaine+fentanyl.

PACU, postanesthetic care unit.

No of rescue analgesia, number of patients receiving supplementary analgesia.

There are no significant differences between the groups $(p>0.05)$.

Table 3. Modified Bromage score of lower limbs.

\begin{tabular}{lcr}
\hline & Group R1 $(\mathrm{n}=33)$ & Group R2 $(\mathrm{n}=37)$ \\
\hline At PACU & & \\
0 & $12(36.4)^{\mathrm{a})}$ & $29(78.4)$ \\
$1,2,3$ & $21(63.6)^{\mathrm{a})}$ & $8(21.6)$ \\
At $6 \mathrm{hr}$ & & $26(70.3)$ \\
0 & $12(36.4)^{\mathrm{a})}$ & $11(29.7)$ \\
$1,2,3$ & $21(63.6)^{\mathrm{a})}$ & \\
At $12 \mathrm{hr}$ & & $10(27.0)$ \\
0 & $15(45.5)^{\mathrm{a})}$ & \\
$1,2,3$ & $18(54.5)^{\mathrm{a})}$ & $28(75.7)$ \\
At $24 \mathrm{hr}$ & & $9(24.3)$ \\
0 & $22(66.7)$ & \\
$1,2,3$ & $11(33.3)$ & $7(18.9)$ \\
At $36 \mathrm{hr}$ & & \\
0 & $26(78.8)$ & \\
$1,2,3$ & $7(21.2)$ &
\end{tabular}

Values are presented as number (\%).

Modified Bromage score: 0 , no motor block; 1 , inability to raise extended leg; 2 , inability to flex knee; 3 , inability to flex ankle. Group R1, 0.15\% ropivacaine+fentanyl; group R2, 0.075\% ropivacaine+fentanyl.

PACU, postanesthetic care unit.

a) $p<0.05$ versus the Group R2. 
Table 4. Incidence of side effects in each treatment group

\begin{tabular}{lcc}
\hline & Group R1 $(\mathrm{n}=33)$ & Group R2 $(\mathrm{n}=37)$ \\
\hline No. of patients with Cx & $18(54.5)$ & $15(40.5)$ \\
Dizziness & 1 & 3 \\
N/V & $8(24.2)$ & $10(27.0)$ \\
Hypotension & 1 & 0 \\
Pruritus & 2 & 1 \\
Urinary retention & $11(33.3)^{\mathrm{a})}$ & $2(5.4)$ \\
Numbness of legs & 1 & 0 \\
\hline
\end{tabular}

Values are presented as number (\%).

Group R1, 0.15\% ropivacaine+fentanyl; group R2, 0.075\% ropivacaine + fentanyl.

No, number; Cx, complication; N/V, nausea and vomiting. a) $p<0.05$ versus the group $\mathrm{R} 2$.

Table 5. The dermatome of sensory block

\begin{tabular}{ccc}
\hline & Group R1 $(\mathrm{n}=33)$ & Group R2 $(\mathrm{n}=37)$ \\
\hline T6 & $2(6.1)$ & $3(8.1)$ \\
T7 & $9(27.3)$ & $7(18.9)$ \\
T8 & $13(39.4)$ & $14(37.8)$ \\
T9 & $7(21.2)$ & $9(24.3)$ \\
T10 & $2(6.1)$ & $4(10.8)$ \\
\hline
\end{tabular}

Values are median (range) of number of dermatomes with decreased sensitivity to pinprick.

Group R1, 0.15\% ropivacaine+fentanyl; group R2, 0.075\% ropivacaine + fentanyl.

There are no significant differences between the groups.

\section{DISCUSSION}

This study compared the effects of lower concentration of ropivacaine $(0.075 \%)$ plus fentanyl for PCEA on postoperative analgesia, motor block, and other side effects with higher concentration of ropivacaine (0.15\%) plus fentanyl. Epidural analgesia with $0.075 \%$ ropivacaine provided similar pain relief after gynecologic surgery when compared with $0.15 \%$ ropivacaine. Participants with epidural infusion of $0.075 \%$ ropivacaine presented the advantage of preserving motor control in lower limbs and significantly less incidence of urinary retention than the group with $0.15 \%$ ropivacaine.

Previous studies have reported that epidural infusion of local anesthetics provides superior postoperative analgesia for lower abdominal surgery, including laparoscopic gynecologic surgery, compared with IV-PCA [6,7]. The optimal concentration of ropivacaine has been suggested as $2 \mathrm{mg} / \mathrm{mL}(0.2 \%)$ when used for epidural analgesia $[2,8,9]$; however, this concentration was shown to lead to excessive motor blockade and urinary retention $[1,10]$. Lower concentrations of ropivacaine can be helpful in minimizing motor blockade and other side effects since the concentration of local anesthetic solution is a major determinant of motor blockade with PCEA [2]. Clinical studies evaluating postoperative analgesia demonstrated that a combination of local anesthetic and opioid has synergistic effects [3,5]. Although the action mechanism of epidural opioids is unclear, epidurally administered opioids can improve postoperative analgesia and facilitate the use of lower concentration of epidural ropivacaine with decreased motor blockade. Buggy et al. reported that $0.1 \%$ ropivacaine with fentanyl provided sufficient analgesia after lower abdominal surgery [11].Their results showed that an epidural infusion of $0.1 \%$ ropivacaine plus fentanyl provided similar pain relief when compared with $0.2 \%$ ropivacaine $[1,8]$. In this study, we found that an epidural infusion of $0.075 \%$ ropivacaine plus fentanyl was equivalent to $0.15 \%$ ropivacaine plus fentanyl in terms of pain management after lower abdominal surgery, and both concentrations of ropivacaine provided excellent pain control (Table 2). Therefore, a combination of local anesthetic and opioid for epidural analgesia seemed to improve postoperative pain relief and allow the use of a lower concentration of local anesthetic.

Motor blockade of the lower limbs is a major consideration for epidural analgesia due to the current emphasis on early postoperative mobilization. Lower concentration of local anesthetic can be used for epidural analgesia to minimize motor blockade of the lower limbs. Scott et al. reported that there was a dose-related increase in the amount of motor blockade [9]. Approximately $30 \%$ of patients with an epidural infusion of $0.2 \%$ ropivacaine demonstrated motor blockade of the lower limbs, but the incidence of motor blockade was very low in an epidural infusion of ropivacaine $0.1 \%$. In another study, motor blockade occurred in 30-63\% of patients receiving a lumbar epidural infusion of $0.2 \%$ ropivacaine [1]. Our results also showed that the incidence of motor blockade in the $0.075 \%$ ropivacaine group was significantly lower when compared with the $0.15 \%$ ropivacaine group.

Although PCEA has been considered to be the gold standard for pain management after major abdominal surgery, some studies have shown that many patients suffer various side effects after epidural analgesia $[4,9,11,12]$. Frequent adverse effects include urinary retention, pruritus, hypotension, nausea and vomiting. Common side effects in our study were 
also nausea, vomiting and urinary retention. The total number of patients showing complications was not significantly different between the groups (Table 4). However, urinary retention was more common in the group R1 (epidural analgesia with ropivacaine $0.15 \%$ plus fentanyl, Table 4 ) than the group R2. Local anesthetic block of S2-4 can result in urinary retention by an interference with normal voiding after epidural blockade [2]. A higher concentration of epidural ropivacaine in the group R1 may be associated with higher incidence of urinary retention due to more intense blockade. Turner et al. [8] showed that approximately $10-30 \%$ of patients with epidural ropivacaine $0.2 \%$ experienced urinary retention, but another study reported that $0-1 \%$ of patients with $0.1 \%$ ropivacaine had urinary retention [4]. Nausea and vomiting, which are also common adverse effects, occurred in $25.7 \%$ of all participants, but the incidences were not significantly different between the two groups. Although many factors are related with postoperative nausea and vomiting, opioids can be seen as a major trigger of our study. Nausea has been reported to occur in approximately $23-26 \%$ of patients treated with opioids $[13,14]$, which was similar in our case. Moreover, significantly more patients with larger dose of epidural fentanyl experienced nausea [5]. However, a previous study has reported that a combination of epidural opioids with local anesthetics had little effect on the occurrence of nausea and vomiting in PCEA [12]. Hence, further studies are needed to determine what is responsible for nausea and vomiting after surgery.

In conclusion, this study showed that a lower concentration $(0.075 \%)$ of epidural ropivacaine with fentanyl was not significantly different from higher concentration $(0.15 \%)$ of epidural ropivacaine with fentanyl in terms of postoperative analgesia. Furthermore, the incidence of motor blockade of the lower limbs was lower in the patients with $0.075 \%$ ropivacaine than the patients with $0.15 \%$ ropivacaine. Therefore, a combination of $0.075 \%$ ropivacaine with fentanyl is recommended as an effective alternative to $0.15 \%$ ropivacaine with fentanyl for PCEA.

\section{CONFLICT OF INTEREST}

No potential conflict of interest relevant to this article was reported.

\section{ORCID}

Hyun Chul Jung, https://orcid.org/0000-0002-9613-9626

Sang-Jin Park, https://orcid.org/0000-0002-4838-2664

\section{REFERENCES}

1. Etches RC, Writer WD, Ansley D, Nydahl PA, Ong BY, Lui A, et al. Continuous epidural ropivacaine $0.2 \%$ for analgesia after lower abdominal surgery. Anesth Analg 1997;84:784-90.

2. Butterworth JF, Mackey DC, Wasnick JD. Morgan \& Mikhail's clinical anesthesiology. 5th ed. New York: McGrawHill, 2013. p. 958-72.

3. Matsota P, Batistaki C, Apostolaki S, Kostopanagiotou G. Patient-controlled epidural analgesia after Caesarean section: levobupivacaine $0.15 \%$ versus ropivacaine $0.15 \%$ alone or combined with fentanyl $2 \mu \mathrm{g} / \mathrm{mL}$ : a comparative study. Arch Med Sci 2011;7:685-93.

4. Lee WK, Yu KL, Tang CS, Lee LS, Fang HT, Au CF. Ropivacane $0.1 \%$ with or without fentanyl for epidural postoperative analgesia: a randomized, double-blind comparison. Kaohsiung J Med Sci 2003;19:458-63.

5. Scott DA, Blake D, Buckland M, Etches R, Halliwell R, Marsland $\mathrm{C}$, et al. A comparison of epidural ropivacaine infusion alone and in combination with 1,2 , and 4 microg $/ \mathrm{mL}$ fentanyl for seventy-two hours of postoperative analgesia after major abdominal surgery. Anesth Analg 1999;88:857-64.

6. Cullen ML, Staren ED, el-Ganzouri A, Logas WG, Ivankovich $\mathrm{AD}$, Economou SG. Continuous epidural infusion for analgesia after major abdominal operations: a randomized, prospective, double-blind study. Surgery 1985;98:718-28.

7. Hensel M, Frenzel J, Späker M, Keil E, Reinhold N. [Postoperative pain management after minimally invasive hysterectomy: thoracic epidural analgesia versus intravenous patient-controlled analgesia]. Anaesthesist 2013;62:797-807.

8. Turner G, Blake D, Buckland M, Chamley D, Dawson P, Goodchild C, et al. Continuous extradural infusion of ropivacaine for prevention of postoperative pain after major orthopaedic surgery. Br J Anaesth 1996;76:606-10.

9. Scott DA, Chamley DM, Mooney PH, Deam RK, Mark AH, Hägglöf B. Epidural ropivacaine infusion for postoperative analgesia after major lower abdominal surgery--a dose finding study. Anesth Analg 1995;81:982-6.

10. Zaric D, Boysen K, Christiansen C, Christiansen J, Stephensen $\mathrm{S}$, Christensen B. A comparison of epidural analgesia with combined continuous femoral-sciatic nerve blocks after total knee replacement. Anesth Analg 2006;102:1240-6.

11. Buggy DJ, Hall NA, Shah J, Brown J, Williams J. Motor block during patient-controlled epidural analgesia with ropivacaine or ropivacaine/fentanyl after intrathecal bupivacaine for caesarean section. Br J Anaesth 2000;85:468-70.

12. Liu SS, Moore JM, Luo AM, Trautman WJ, Carpenter RL. Comparison of three solutions of ropivacaine/fentanyl for 
Hyun Chul Jung et al.

postoperative patient-controlled epidural analgesia. Anesthesiology 1999;90:727-33.

13. Cepeda MS, Farrar JT, Baumgarten M, Boston R, Carr DB, Strom BL. Side effects of opioids during short-term administration: effect of age, gender, and race. Clin Pharmacol Ther
2003;74:102-12.

14. Meuser T, Pietruck C, Radbruch L, Stute P, Lehmann KA, Grond S. Symptoms during cancer pain treatment following WHO-guidelines: a longitudinal follow-up study of symptom prevalence, severity and etiology. Pain 2001;93:247-57. 